Paper ID \#18405

\title{
Design \& Development of a 3D-Printed Quadcopter Using A System Engi- neering Approach in an Electrical Engineering Master's Capstone Course
}

\section{Prof. John M Santiago Jr, Colorado Technical University}

Professor John Santiago has been a technical engineer, manager, and executive with more than 26 years of leadership positions in technical program management, acquisition development and operation research support while in the United States Air Force. He currently has over 16 years of teaching experience at the university level and taught over 40 different graduate and undergraduate courses in electrical engineering, systems engineering, physics and mathematics. He has over 30 published papers and/or technical presentations while spearheading over 40 international scientific and engineering conferences/workshops as a steering committee member while assigned in Europe. Professor Santiago has experience in many engineering disciplines and missions including: control and modeling of large flexible space structures, communications system, electro-optics, high-energy lasers, missile seekers/sensors for precision guided munitions, image processing/recognition, information technologies, space, air and missile warning, missile defense, and homeland defense.

His interests includes: interactive multimedia for e-books, interactive video learning, and 3D/2D animation. Professor Santiago recently published a book entitled, "Circuit Analysis for Dummies" in 2013 after being discovered on YouTube. Professor Santiago received several teaching awards from the United States Air Force Academy and CTU. In 2015, he was awarded CTU's Faculty of the Year for Teaching Innovations. Professor Santiago has been a 12-time invited speaker in celebration of Asian-Pacific American Heritage Month giving multi-media presentations on leadership, diversity and opportunity at various military installations in Colorado and Wyoming.

\section{Dr. Kathy L. Kasley P.E., Colorado Technical University}

Kathy Kasley earned her BS in Mathematics from Ursinus College, a Master's Degree in Mathematics at Villanova University, a Master's Degree in Electrical Engineering from the University of Colorado in Colorado Springs, and her Ph.D. in Electrical Engineering from the University of Colorado. Dr. Kasley is a Professional Engineer, and has a Consultant-Evaluator for the Higher Learning Commission of the North Central Association of School and Universities for over 15 years. Dr. Kasley has taught mathematics and Engineering at high school, and at the university level for over 25 years. She has served as an instructor, academic adviser, ADA student counselor, and dean or chair of Engineering. 


\title{
Design \& Development of a 3D-Printed Quadcopter Using a System Engineering Approach in an Electrical Engineering Master's Capstone Course
}

\author{
John Santiago, Jr., Ph.D. Kathy Kasley, Ph.D., and Shahram Tabatabaei \\ Colorado Technical University (CTU), College of Engineering, Colorado Springs, CO
}

\section{Introduction}

The paper describes the shift in emphasis in the University's Master of Science in Electrical Engineering program, as well as details of the capstone course which had been used for the assessment of the program. This change embodied moving the emphasis from extensive technical detail to focus on the design and development process, and is illustrated by the creation of a 3D-printed quadcopter by one student. The capstone has been revised around the Vee Model to describe systems engineering process. The top-down and bottom-up design perspectives are compared, and weekly deliverables are presented to help students practice systems engineering. A detailed description of weekly deliverables and rubric for the Critical Design Review are described elsewhere ${ }^{1}$. Two perspectives of the Vee-Model are described to provide a holistic perspective of system-level thinking ${ }^{2-4}$. A 3D-printed quadcopter with its stable flight control are provided as an illustration of the student efforts. ${ }^{5}$ Major blocks of the system include: (1) the quadcopter frame, (2) the control system, and (3) the power and thrust system.

The last part of the paper attempts to compare the Vee Model system engineering approach with alternative implementations of the capstone engineering courses by other colleges and universities $^{6-13}$. Specifically, any capstone projects involving 3D printing and Arduinos to design a quadcopter are investigated and summarized ${ }^{13-23}$. The paper also attempts to compare the student's prototype with other popular commercially available quadcopters, including some cost comparisons ${ }^{24}$.

\section{Description of the Original Master of Science in Electrical Engineering}

University’s Master of Science in Electrical Engineering program offers an in-depth understanding of modern systems design for emerging and evolving technologies. Students experience design projects in digital, spreadspectrum and space communications, CMOS circuitry and computer architectures. Further, students develop essential project management and leadership skills designed to give them a competitive edge higher-level engineering roles. The Master of Science in Electrical Engineering degree is focused on providing an overview of industry-relevant approaches for those who aspire to work in electrical engineering.

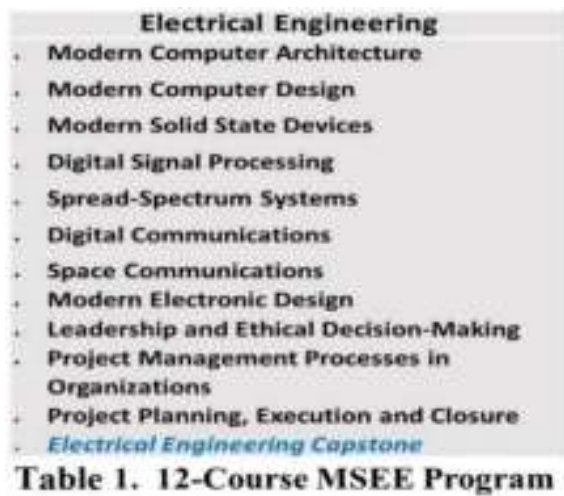

Table 1. 12-Course MSEE Program 
The Master Program in Electrical Engineering consists of twelve courses given in Table 1, requiring the successful completion of an 11-week capstone course. The capstone project is a system-level solution to a relevant current problem.

\section{Capstone Course Description and Course Objectives}

The capstone course offers the student the opportunity to integrate skills developed throughout the Master's program and practice project management skills by completing a project that focuses on a current issue in engineering. The students must: define the problem or opportunity, identify constraints, complete an analysis, prepare and deliver a professional report, and prepare and deliver professional presentations.

The objectives of the course encourage the student to consider problem solving from a broader, system-level approach:

- Frame an ill-defined engineering problem and define appropriate requirements that the solution must satisfy

- Design and implement a test protocol to verify that the designed system meets the defined requirements

- Design and/or model a system to meet the defined requirements

- Integrate skills, concepts, and/or tools acquired in prerequisite coursework and apply the same to successfully complete the project

- Independently acquire any additional skills, concepts, and/or tools necessary for successful project completion

- Communicate regularly with the faculty mentor and keep a journal of all work completed in the project

- Communicate the results of the project to peers and mentors through an oral presentation and a technical report

The course deliverables listed in Table 2 includes: Project Plan and Journal (22.5\%), Communication Skills (47.5\%) and Technical Merit (30\%). Students must take an illdefined problem and follow a system engineering approach to implement a proof-of-concept solution.

\section{Why Apply Systems Engineering Concepts?}

Observations made during assessment of the University's Master of Science

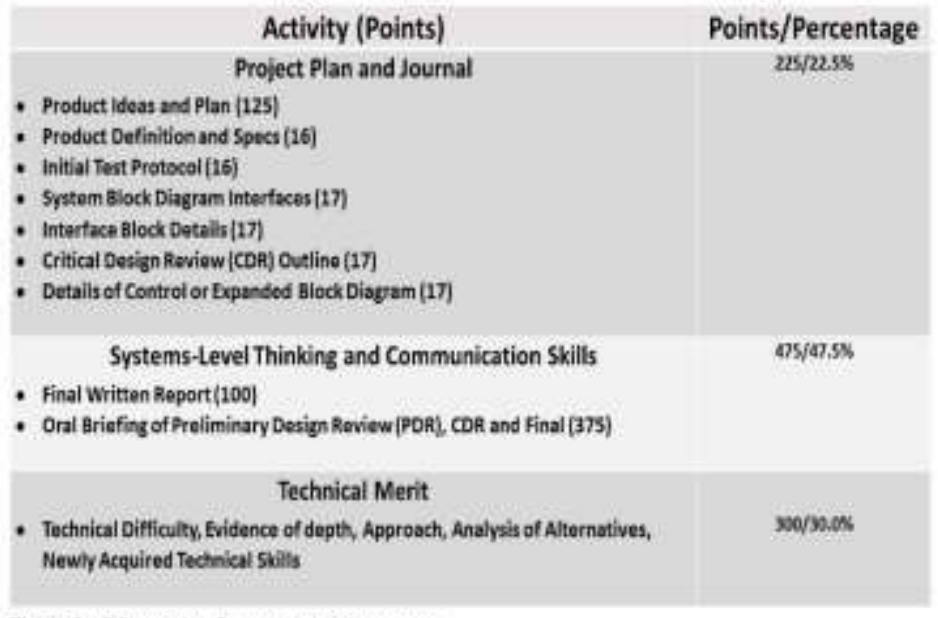

Table 2. Measuring Learner Achievement in Electrical Engineering program highlighted a significant improvement in the quality of the student capstone when the students elected to substitute systems engineering courses for the 
project management courses. Projects tended to be more organized, and include stronger evaluations of practicality and performance of the final project.

The Professors Santiago and Kasley have instructed several graduate several courses in electrical, computer and systems engineering, and observed the improvement in student work when challenged to use of system-level thinking. This provided one key reason why engineering faculty wanted to adopt a system engineering approach. In addition, the local campus has a heavy military presence, and systems engineering course deliverables better match defense or government expectations while stressing the importance to improve written and oral communications skills.

In the past, during the advising process, some students requested systems engineering courses as substitutes for project management based on their experience. Program management handles the day-to-day activities of a technical project such as balancing the schedule, cost and technical system performance. Systems engineering takes a longer, broader perspective and includes system life cycle, affordability, usability, reliability, maintainability, supportability, manufacturability, and disposability ${ }^{1}$.

Thus, systems engineering requires spending more time on the initial project/program planning and less focus on day-to-day activities. Within this context, project/program management can be viewed as a subset of systems engineering during use and maintenance after development of the system. Project or program management is integrated within the systems engineering courses using appropriate textbooks ${ }^{2-4}$.

\section{The Systems Engineering Approach}

In order to promote the systems engineering approach, the College of Engineering began by changing the required courses from project management course to the first two system engineering courses. Then, the capstone was revised to follow the Vee Model from systems engineering. The perceived benefits of implementing systems engineering concepts include:

- Shift students' focus from technology solution to what system must do (e.g. requirements)

- SE helps with planning, organizing, executing and evaluating a project

- SE provides structure through weekly deliverables to guide students throughout a project from start to finish

- The heavy military presence within the area values a system engineering perspective to meet their defense requirements

Many times, students are engrossed on a final solution or technology when first starting a project. The students are focused on the 'how', preferring to apply a technology of interest without consideration of a market or customer need. This initial approach by the student may be viewed as bottom-up thinking as shown in Figure 1. 
The shift requires students to focus first on the 'what' during the initial stage of the project: that is, what functions must the system perform to meet customer requirements. This view of market or demand push is known as top-down thinking. These two rival views are commonly known to industry as: technology push versus requirements pull (or market/demand pull). Figure 1 gives a picture of these two point of views. A system engineering approach expands student learning by emphasizing a system engineering

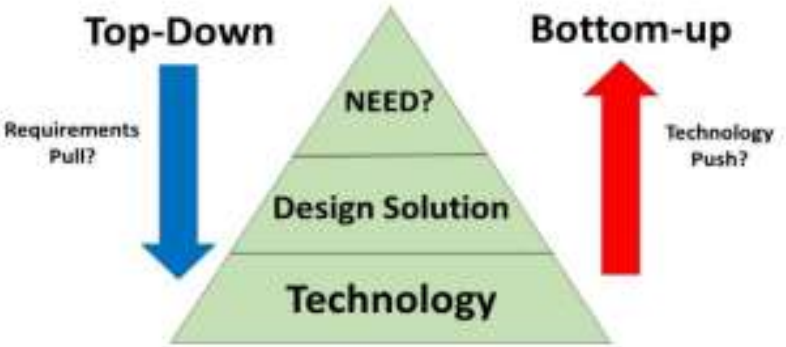

Figure 1. Technology Push versus Requirements Pull and holistic perspective while building upon specialized skills.

Table 3 identifies the schedule of student work and illustrates the systems engineering process. This approach is structured by having weekly deliverables but flexible in terms of the technical content.

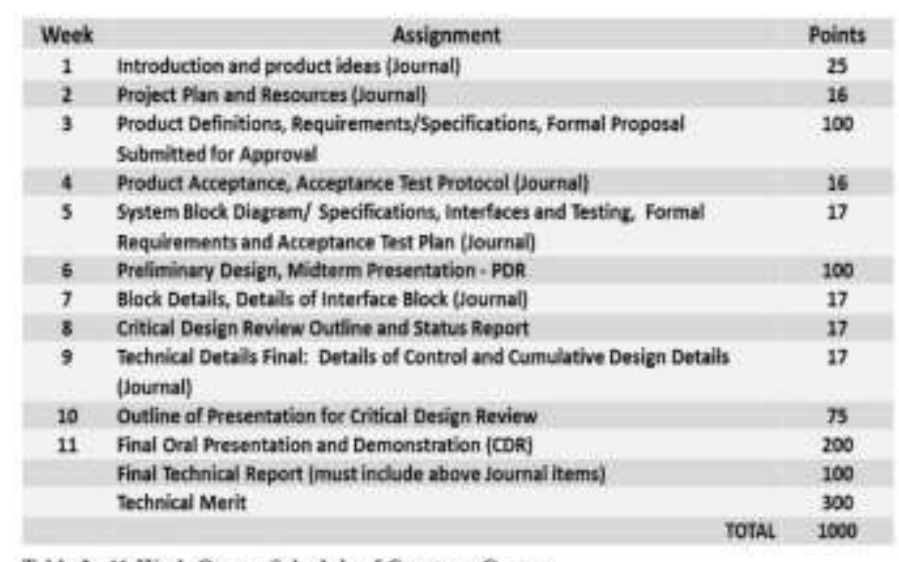

Table 3. 11-Week Course Schedale of Capstone Course
The methodology attempts to provide a balanced approach that includes technical merit, system-level thinking, and improved communication skills. In systems engineering processes, there are numerous design documents and reviews during the acquisition of a system. Consequently, the systems engineer must be an accomplished communicator interacting with individuals with various skill sets. Electrical and computer engineering students, especially those who are international students, may be unfamiliar with the systems engineering processes. To assure that graduates are truly prepared, the weighting and weekly deliverables allow students to practice systems engineering. A step-by-step and iterative plan helps students expand their perspectives in engineering as systematic processes that deliver the system solution to the marketplace. The structure drives students to shift from a technologyfocused solution to one that addresses customer needs. The College of Engineering values both bottom-up and top-down approaches used in combination. A detailed description of the weekly deliverables is given elsewhere and will not be described here due to space limitations ${ }^{4}$. The Critical Design Review (CDR) rubric was also developed to balance the course weighting between system-level thinking fostered by weekly deliverables and acquired technical skillsets from the MSEE program ${ }^{4}$. The weekly deliverables are guided by the Vee Model ${ }^{1-3}$.

\section{The Systems Engineering Process and the Vee Model $^{2-4}$}

Figure 2 depicts the systems engineering Vee-Model from a testing perspective shown in Figure $2 \mathrm{a}$ and from an architecture perspective $\mathrm{e}^{2}$ as shown in Figure $2 \mathrm{~b}$. 
In Figure 2a, the Vee-Model looks at the system, subsystem and component level of testing. The model starts with an identification of user needs on the upper left and ends with a fully system-level acceptance testing and evaluation on the upper right. Advancing down the left side of the Vee-Model is the decomposition of the system into subsystems, and then into components. The technical activities involve defining and resolving the system architecture to mature the design (or definition) of the system with increased fidelity.

The right ride of the Vee-

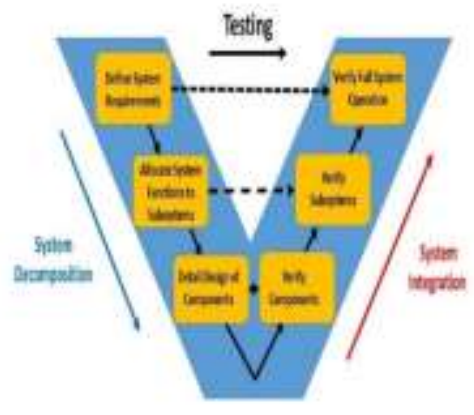

Figure 2a. Teating Perspoctive

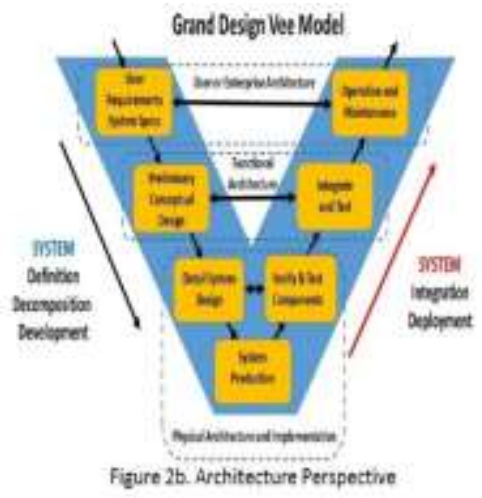

Figure 2. System Engineering Process "Vee" Model: Testing1 and Architecture² Perspective model in Figure 2a involves the integration of system components with testing, moving upward to the subsystem and finally the system level. The testing process flows up and to the right as higher levels of subsystems are verified. Finally, the system level is validated through user acceptance testing and evaluation. The user acceptance test plan insures overall specifications are met while testing is performed at all-levels: component, subsystem and system level. The test plan verifies and validates the entire the system in preparation for user acceptance.

The 'Grand Design' and architecture perspective ${ }^{2}$ is shown in Figure 2b. The definition of the system begins with ' $w$ hat' functions the solution must perform to define an initial functional architecture. These functions are collected and allocated to a subsystem which further defines the functional architecture. Defining the functional architecture increases the system fidelity and definition during the design stage. The subsystem functions are further decomposed to identify (or design) physical components (hardware/software) which defines the lowest physical architecture. At this point, the physical architecture describes 'how' the system solution is implemented. Moving up to the upper right of the Vee Model, components are tested and integrated, tested and integrated up to the full system level. The result is an enterprise architecture, deployable for intended stakeholders.

The following section describes the activities or deliverables involving systems engineering activities for each week. Students are encouraged and advised several weeks before the capstone quarter to begin thinking about their project so they are well-prepared to start quickly. The student must design a new product, and either demonstrate how it behaves or model its performance. Several self-motivated and talented students followed this advice and successfully completed technically challenging projects while following the systems engineering process.

\section{Summary of the 3D-Printed Quadcopter Project}

Through his twenty-six years of experience in the US Air Force, the Professor Santiago has observed the military operating drones to accomplish dangerous missions for several decades. 
Currently, USAF is ordering new drones at a higher rate with increased capabilities to accomplish the mission at a lower cost with no risk to their pilots or airmen ${ }^{5}$. Of course, robots lack creativity and are limited to the knowledge and logic given to them by their human creators.

During 2014, graduate students were encouraged to consider potential capstone projects. Professor Santiago provided examples of IEEE (Institute of Electrical and Electronic Engineering) projects from the student branch. The presentation showed videos about how a team of quadcopters working together to perform athletic feats from University of Pennsylvania and Swiss Federal Institute of Technology (ETH Zürich).

After the presentation, one exceptional and motivated MSEE student built a 3D-printed quadcopter over three quarters. The student started working his project to acquire technical skills prior to the capstone course.

Market research showed the cost savings of quadcopters used to monitor the hot-spots following the devastating fires in Colorado currently done with helicopters and boots-on-the-ground firefighters. Other drone applications included law enforcement and search and rescue. The scale and technical requirements of these types of projects illustrate the learning outcomes expected in the capstone course. In this project, the student learned how to build a 3D-printed quadcopter, taught himself about control theory not covered in the Master's Program, and then implemented flight control of it using an Arduino microcontroller. During the project, the

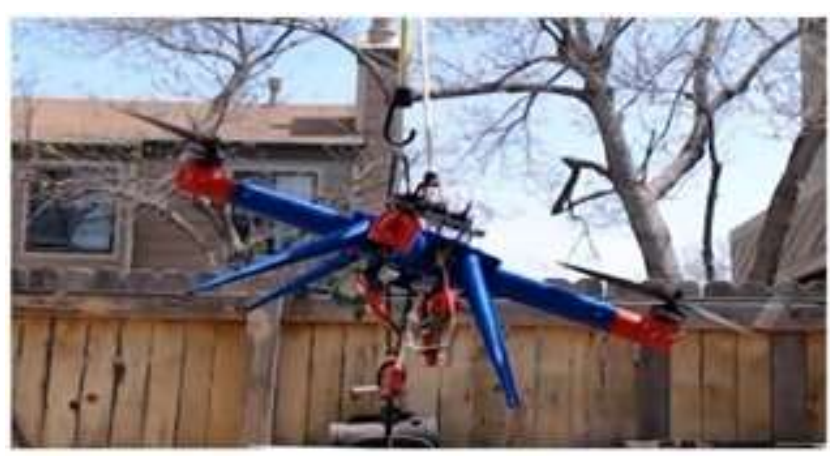

Figure 3 Initial One-Dimensional Testing of Tethered 3-D Printed Quadcopter \& Control Strategy student developed a temperature control system to improve the 3-D printed parts for the quadcopter. After building the 3D-printed parts, he integrated the motors and Arduino controller. He tested his control algorithm to orient and stabilize the quadcopter at fixed and varying angles input by users. This included tethering the quadcopter to validate onedimensional control so that the quadcopter can fly stably. Figure 3 shows the quadcopter testing the controller for a fixed angle. The student tested his control algorithm in two-dimensions, and successfully demonstrated the untethered quadcopter in three-dimensions. In addition to the technical skills learned prior to the capstone course, the student follow a system engineering approach to develop a set of specifications, determined the subsystems, integrate the components and demonstrate the proposed drone prototype.

The system engineering process is illustrated by samples of the information provided in the student weekly deliverables.

High-Level Cost Comparison of Design Alternatives. During the final presentation, the student provided a cost comparison between commercially available drones and the 3D-printed project. His main points when looking at commercially available drones are: high cost - $\$ 10,000$ to 
$\$ 30,000$ and more, proprietary hardware and software, the parts not repairable, and there is a monopoly for spare parts. He concluded that the market needs an alternative. Compared to large corporate suppliers for a quadcopter, the 3D-printed material can be used to build highly customizable and inexpensive spare parts. The material is relatively easy to repair as well as being recyclable. In the student's design, he used readily available computers, sensors, radio, motors, ESCs and propellers. Using this approach, the student found that that cost of the 3Dprinted quadcopter is estimated to be cheaper that cost less to maintain and provides more freedom to customize to meet evolving requirements. The student's approach serves as an alternative to big corporate manufacturers.

Other materials were investigated to build the frame for the quadcopter including: carbon fiber, aluminum, fiberglass, polycarbonate, balsa wood, steel and titanium. Considerations were given to dollar cost, weight, ease of repair, strength or stiffness, and ease of construction. Other design alternatives were explored and design tradeoffs among helicopters, bi-copters, tri-copters and quadcopters were compared in terms of lift, robustness, stability and control.

\section{Initial Concept of the Capstone Project}

An autonomous and programmable drone that is a slow-flying drone to provide an eye-in-the-sky where it is needed. For example, to help find missing people in the woods, assist in locating smoldering hotspots related to wildfires or provide aid to police in pursuing criminals are some applications.

Here is the student deliverable of the project idea required for the capstone course ${ }^{5}$ :

"The biggest appeal of robots is the fact that they are capable of doing massive work with high accuracy and no need for personal time, rest, healing, dealing with family and so much more. All those factors lead to a top of the line productivity that is unmatched by any human being. They are also great doing dangerous jobs that could cause injury or death to humans. The dream of fighting wars without putting soldiers' lives in danger is an old one but it is getting closer to reality every day. The US Air Force has been operating drones to accomplish dangerous missions for a while now and is ordering new drones at a higher rate because they accomplish the mission for much cheaper and no risk to our pilots and airmen. Of course, robots and in a more general way computers lack creativity and are limited to the knowledge and logic given to them by their human creators. In addition, the idea of an autonomous flying machine has been an intriguing thought for the student since he was eight years old when his dad bought him a Styrofoam plane model. Creating new machines was one of the reasons that he started studying engineering in the first place and remains his motivating force today."

The proposed project was a quadcopter capable of taking off and flying to a target and hovering over it. The quadcopter would then return to base and land safely while carrying a camera. The quadcopter would provide a birds-eye view for the operator a recording capability video and other onboard telemetry. To build the drone, the student estimated the following system-level resources: 
- An appropriate frame to provide support for components

- Motors to provide the required lifting force

- Batteries to provide power

- Computers to deliver command and control operations

- Radio to provide wireless communications

- Different sensors to provide information for the computers

- Propellers in providing lift

- Measurement and diagnostic equipment

- Powered hand tools

After several iterations during the first three weeks, the student came up with a following program plan that included the problem, identified users and beneficiaries, product description, product specification, initial test plan for acceptance plan.

The Problem. In a lot of situations there is a need to have a birds-eye view to observe, surveil, chase or organize from the above. The tool of choice for these situations has been helicopters. There are many disadvantages to using a helicopter, flying a helicopter is expensive, labor intensive, a well-trained pilot must be present, helicopters are big and need a lot of room to maneuver and more. That is why a lot of smaller police departments, first responders and private companies are not able to own and maintain a helicopter. An autonomous multi rotor copter is a perfect solution to this problem. It can be built in different sizes to fit every need, it could be as small as the palm of your hand and as big as a helicopter. It could be battery or gas engine powered. The amount of training needed to fly a drone is significantly less than a pilot. The maintenance for a UAV is much easier and cheaper than a helicopter. But the biggest advantage of all is the fact that flying a UAV will not put any body's life in danger and in a case of an accident, there would only be financial losses and much less than a real helicopter. That is why commercially available and affordable UAVs in different sizes and capacities capable of using a variety of accessories to accomplish a vast range of missions are the best solution for any situation that calls for low cost aerial capabilities

Users and Beneficiaries. There are three groups of people who will be impacted by this product. Direct users who are operators of the UAV benefit greatly from it. It enables them to accomplish what they would not have been able to do without spending a lot of money to rent or buy a helicopter and in some cases at all. The second group impacted by this product are the indirect users whom would receive services provided by the UAV which is operated by the first group mentioned earlier. For example, a lost kid who is found by a police UAV carrying an IR camera at night. The third group of beneficiaries are people who design, build and sell these vehicles. 
Product Description. The product is an autonomous quad copter capable of carrying a payload while flying and hovering per GPS coordinates or user commands. The product is capable to do different missions using appropriate accessories, for example a camera, a box of tools or a robotic arm. It could be programmed to fly to different places, per GPS coordinates and fly back home. It could also be controlled using a remote controller.

Product Specifications. The following specifications for the proposed project are as follows:

Dimensions: $\quad 27$ " $\times 27$ " x 14 " $(685 \mathrm{~mm} \times 685 \mathrm{~mm} \times 355 \mathrm{~mm})$ without propellers 39 " x 39" x 14" (990mm x 990mm x 355mm) with propellers

Weight: $\quad 6 \mathrm{lbs} .14 \frac{1}{2} \mathrm{oz}$. (3132.5 gr.)

Power: $\quad 1 \mathrm{~kW}(\operatorname{Max})$ 500 watts (Min)

Rotors: $\quad 4$

Motors: $\quad 22$ pole, out runner, brushless, $17 \mathrm{~V}$ (Max), 250 watts (Max)

Propellers: $\quad 14$ " x 4.7 " - Composite 6000 RPM (Max)

Battery: $\quad 2$ x 8000 mAh (C) 4S LiPo 10C (Max)

Controller: $\quad 2 \times$ Atmel SAM3X8E ARM Cortex-M3 CPU on Arduino Due development board @ $84 \mathrm{MHz}$

Wireless: $\quad$ XBee pro $60 \mathrm{~mW}(802.15 .4)$

Acceptance Test. Since this is a project requiring new technical skills the following acceptance tests were proposed. The student also created videos on the test results and uploaded to YouTube for instructor viewing since the student resides about sixty miles from the campus. The 'Basic Acceptance Test' includes:

- Successful wireless communication between the base and the quadcopter. Sending commands and receiving appropriate responds

- Successful take off

- Successful flight between two points on the ground.

- Successful hover

- Successful landing

Successful mission. A successful mission is defined as follows: a successful take off, ascend to planned altitude, fly to waypoint one, fly to waypoint two, fly back home and land safely.

\section{Concept of Operation.}

In general, a multirotor unmanned aerial vehicle is designed to carry equipment to support a specific mission. Unlike a fixed wing drone that needs to maintain an air speed to stay in the air, the multirotor drone is capable of hovering at any given position and altitude. This capability makes the multirotor drone favorable when the mission requires flight in a tight space such as an urban or tree covered area. This capability comes with a price, namely, the energy inefficiency of a multirotor. This project attempts to explore the design of such unmanned aerial vehicle. 


\section{System Requirements and System Diagram 5}

Figure 4 shows the major subsystems and components of the subsystem as defined by the student.

Table 4 lists the general system requirements and description of the 3Dprinted quadcopter from the student.

The next section will describe a summary of the quadcopter frame.

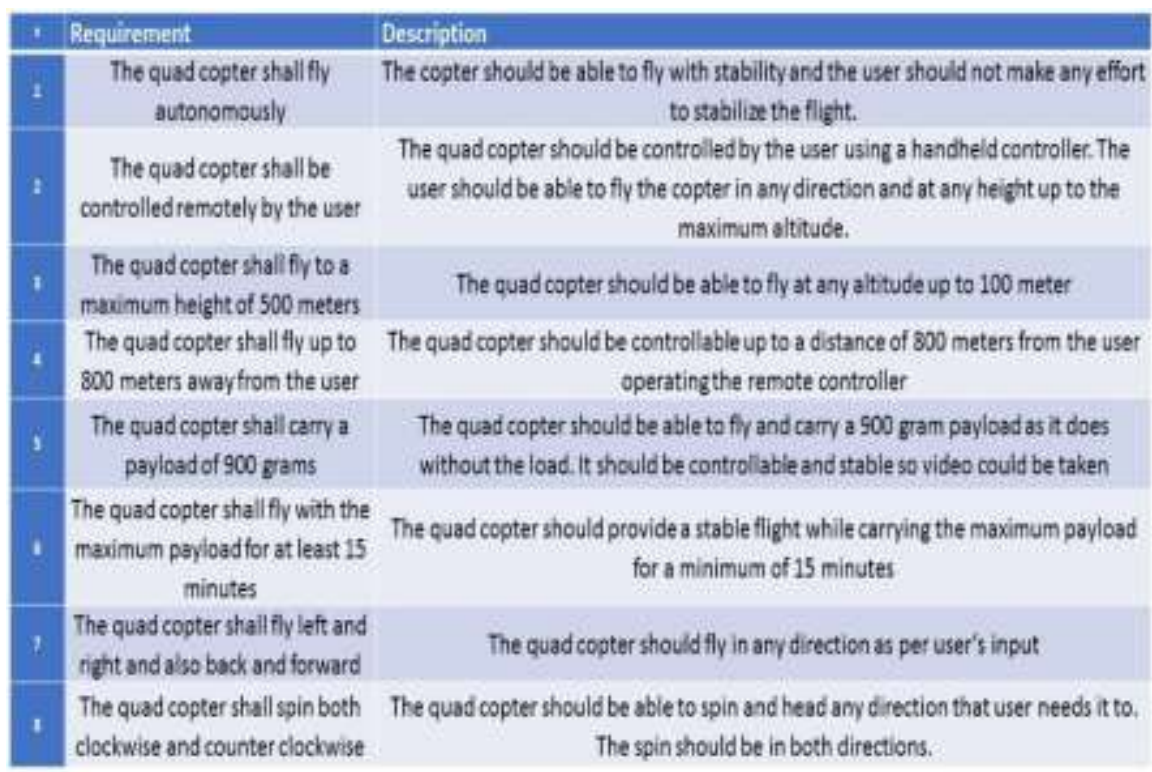

Table 4. System Requirements

\section{The System - Block Diagram}

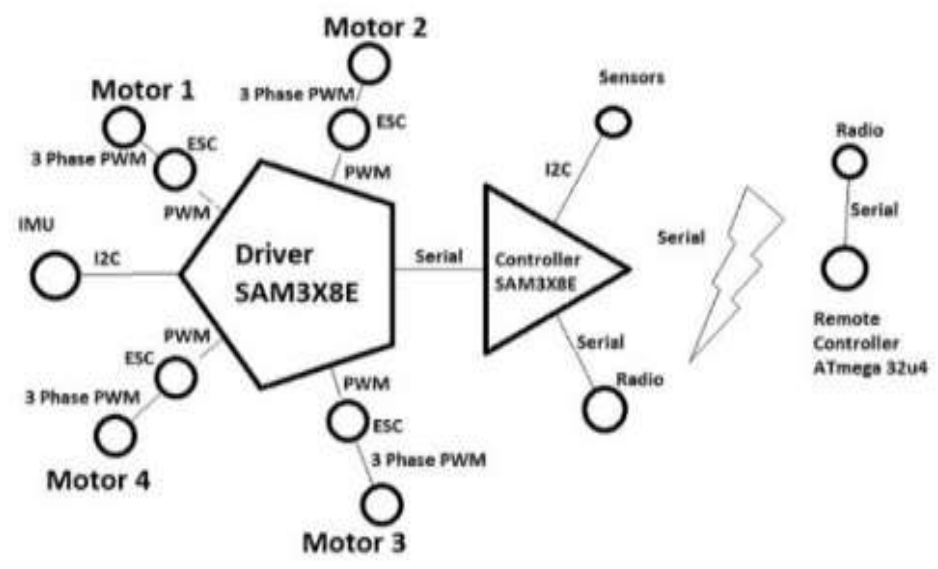

ESC - Electronic Speed Control

PWM - Pulse Width Modulation

SAM3X8E Driver - Arduino Due

SAM3X8E Controller - Arduino Due

Atmega 32u4 - Arduino Esplora

\section{Figure 4. System Block Diagram}

\section{The Frame ${ }^{5}$}

The student had to learn 3D-software and the process of making a 3D-printed quadcopter since the College of Engineering currently does not provide this area of instruction. The student purchased his own 3D-printer and started investigating the building of a quadcopter. Figure 5 shows a 3D-printed Copter created from AutoCAD software. The student learned that building the parts of this size required careful temperature control. Consequently, he built a transparent enclosure for his 3D-printer to help maintain the temperature when printing the 3D parts.

Based on the student's previous design iterations, the student developed the following requirements or specifications for the frame of the quadcopter, depicted in Table 5. 


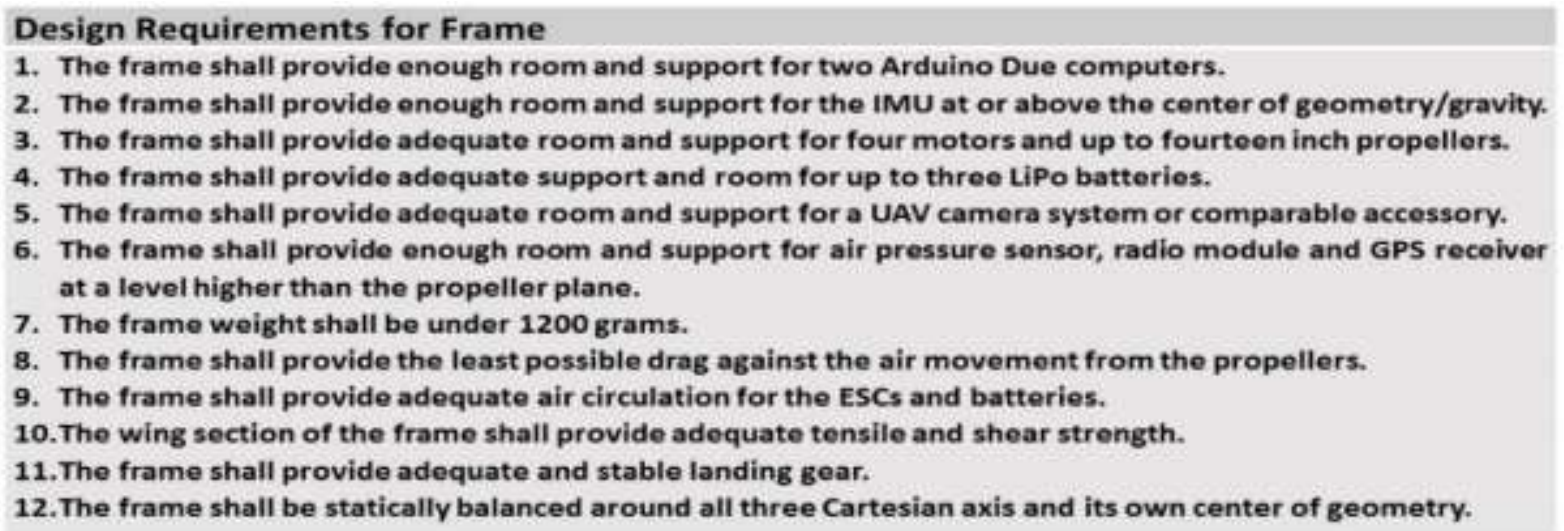

\section{Table 5. Frame Requirements for the 3D-Printed Quadopter}

Build Material and Process. The choice of frame material is an important part of the design. Student research on common materials found a combination of carbon fiber and aluminum or plastic. Since the project involved a lot of prototyping and trials, the cost, lead time, reparability, and the dynamic and fast changing nature of this project demanded a flexible option. The student investigated plastic objects, built using injection molding. Producing one or two parts using this process is very costly and time consuming since every change to the parts will require a new mold.

3D printing has become latest tool to prototype and test ideas. The design of copter frame parts used Autodesk Inventor professional 2014. The size of each 3D-printed part was adjusted to fit the build volume and limitations of the printer, and a few of the major frame components need to be segmented into separate parts, which were then connected using fasteners. The size and shape of parts were edited or completely changed during the design and build process to address practical and performance issues. The 3D-printed quadcopter is shown in Figure 5 displayed with key components shown on the figure. The parts were 3D-printed using an ABS filament in two colors, dark blue and red. Major 3D-printed parts include:

Body Plates. The quadcopter body is made from two octagonal plates which provide support for different parts and components of the quad copter.

Landing Gear Leg. The landing gear system consists of a set of four legs which mount on the body part to provide balance and support for the quad copter on the ground.

Quadcopter Wing. The set of four wings provide a platform for the motor mounts at appropriate distance from the body. They also house the ESC and provide a conduit for the signal and power conductors.

Sensor Tower. The sensor tower provides a mounting platform for the radio module, GPS receiver and air pressure sensor at a level higher than the propeller plane to provide those sensors with less air turbulence and better line of sight either to the ground station or to the satellite. 
Motor Mount. The set of four motor mounts provide the platform for motors to be attached at the end of the wing. They also provide a conduit for the power conductors for the motor and provide ventilation and air circulation inside the wing where the Electronic Spring Control (ESC) is housed.

\section{Batteries and Accessories Mount.}

The set of battery/accessories mounts

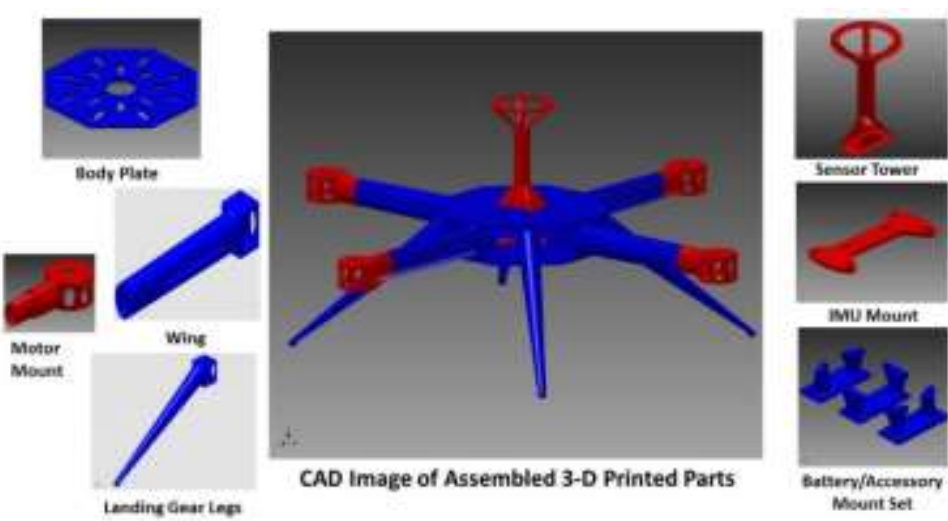

Figure 5. CAD Image of Student Designed Parts of 3D-Printed Quadeopter provide means for mounting different size batteries and accessories. There can be any number of them installed at any given time to accommodate any configuration requirement. Figure 5 shows a set of batteries/accessories mounts.

IMU Mount. The IMU mount provides a platform for the IMU sensor to be mounted at or above the center of geometry of the frame.

\section{Description of Control System and its Elements.}

The control system in this project handles the flying maneuvers through wireless communications with the ground station, satellite, and other sensors along its path. In addition, other components gather data, communicate, measure, and performs real-time calculations to produce output commands power for the multirotor system.

A block diagram of the Control System is shown in Figure 6.

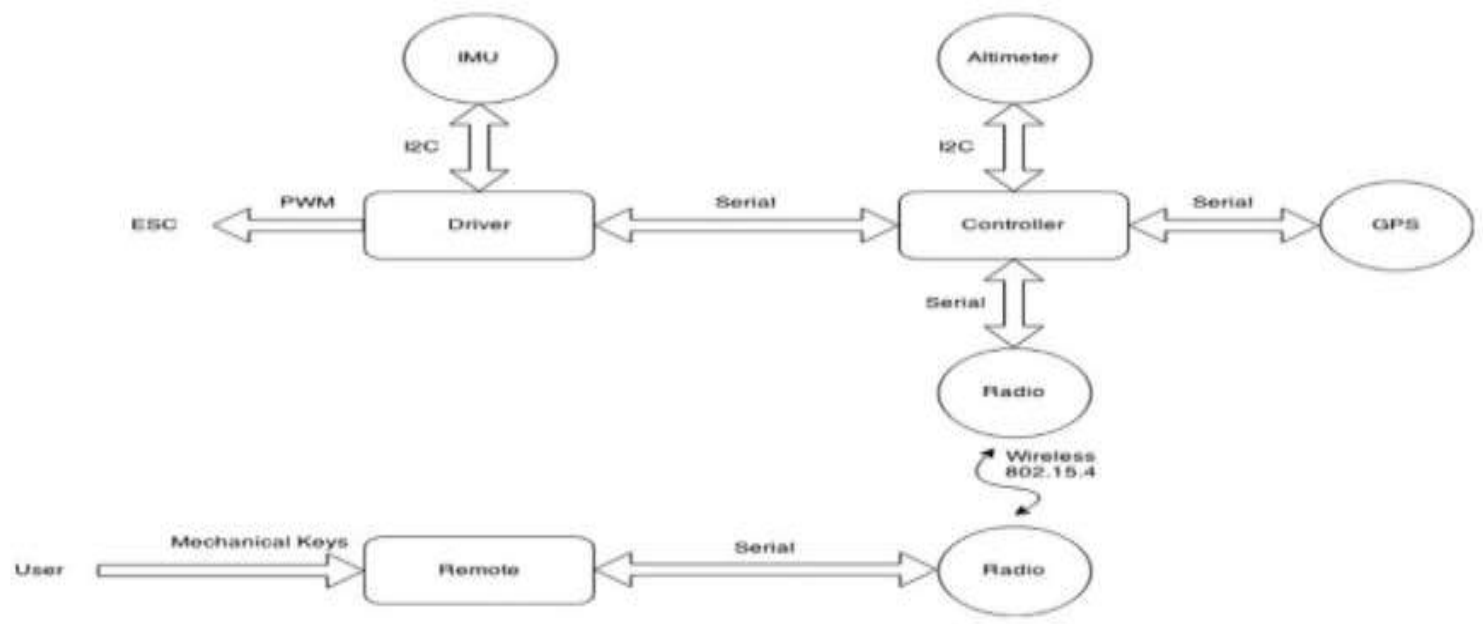

Figure 6. Block Diagram of Control System

The control system uses two types of digital serial communication, asynchronous serial and I2CAsynchronous serial communication (such as USB or Ethernet) allows transmission of information between the ground and on-board microcontrollers through a wireless link. Asynchronous serial protocol has built-in rules to help ensure robust and error-free transmission. 
Inter-integrated Circuit (I2C) protocol intended to allow multiple digital circuits to communicate with one or more integrated circuits.

Depicted in Figure 7 are the various components of the communications. The controller system includes the following:

The on-Board Driver

Controller that drives the multirotor propeller system using real-time operation and to power up the propeller system.

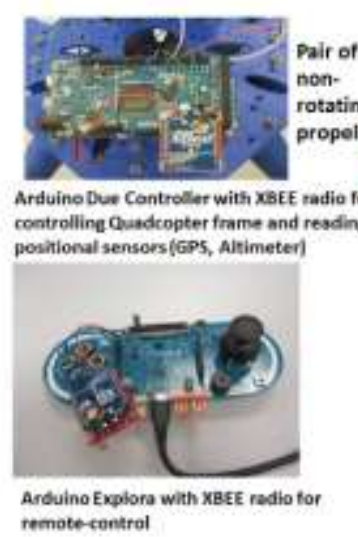

Figure 7. Major Components of Controller System

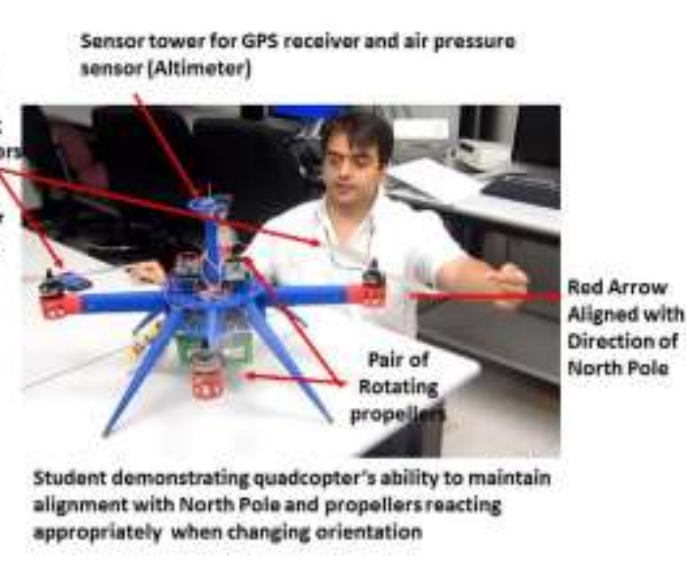

The Ground-based Controller manages the wireless communication. This controller gathers GPS and altimeter information to calculate the positional commands necessary to orientate the 3D-quadcopter.

Inertial Measurement Unit (IMU) with three independent sensors for each axis: accelerometer, gyroscope and magnetometer. Each sensor provides accurate attitude estimations for the copter frame while removing sensor noise and drift.

The Altimeter (MPL3u5AS2) measures air pressure to calculate the altitude. The device also provides a 12-bit temperature measurements in degrees Celsius.

The Radio Module (2.4 GHz XBeeP24-AWI-001) provides a wireless link between the ground station and sensors with the quadcopter. The radio module supports point-to-point or multipoint networks.

Remote Controller (Arduino Esplora, ATmega32u4) translates user inputs into command signals for the quadcopter.

\section{Power and Thrust System}

The components of the power and thrust systems are depicted in Figure 8. The components are:

Lipo Batteries provide the best weight to capacity ratio of rechargeable batteries and provide high

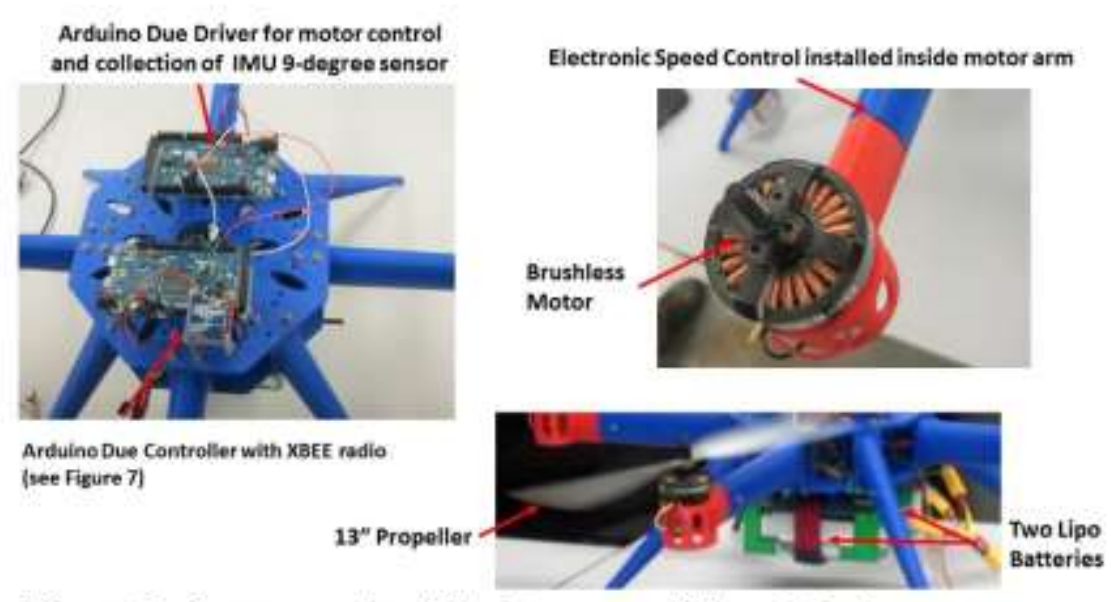

Figure 8. Components of the Power and Thrust System. 
discharge rates. Key components of the Power and Thrust System are shown in Table 6.

ESC and an 'H-bridge' provide speed control. Using PWM and three-phase signals from the microcontroller, the H-bridge switches power for the motors.

The propeller generates thrust to lift the quadcopter, providing low pressure either on top or below the blade plane.

\section{Weight Estimation 5}

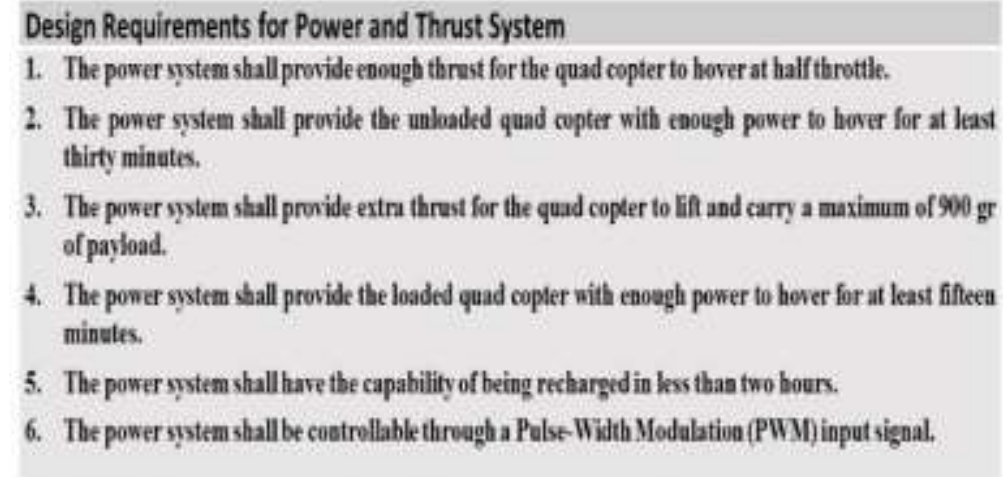

Table 6. Requirements for the Power and Thrust System

A smaller and lighter quadcopter can use a smaller voltage, so there is a need to estimate the weight of the components. Table 7 shows a list of known components and their weight. The

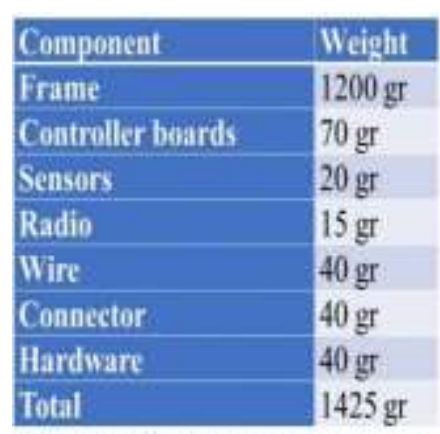

Table 7. List of known components and their weight. estimated weight of the total system was 3200 grams and with a 900 -gram payload the total weight is 4100 grams.

$\frac{\text { Total Weight }}{\text { Number of Rotors }}=$ Amount of thrust for each motor at half - throttle

The manufacturer of propellers recommends calculating the RPM limit for the "slow using the following formula:

$$
\text { Maximum RPM }=\frac{65000}{\text { Prop diameter }(\text { inches })}
$$

Based on manufacturing data and using the above formulas to meet requirements, propeller sizes between 13 " and 14 " are needed. The student performed detailed design calculations on selecting the propeller, ESC, and battery to meet the system requirements. Lessons Learned or conclusions

\section{Lesson learned on the design process}

1. The process of designing a system involves different stages. The first stage is to put all the known elements and requirements together and try to come up with estimations for unknown elements.

2. The design process is iterative. Estimate the unknown elements, design the system, evaluate the performance, refine the estimates, redesign the system, reevaluate the performance, repeat the process until the performance satisfies the requirements.

3. The design process involves elements that are not entirely known or under our control. That is why every design is a compromise between requirements and imperfect solutions.

4. The first design of any product is the most difficult stage. Further design improvements or redesigns of the same product are much easier and more effective.

5. There is always more than one way to solve a problem or design a product according to the requirements.

6. Creating a new product or inventing a novel system is the most exhilarating thing in the world.

\section{Table 8. Lesson learned from the 3D-printed quadcopter project}

made by the student made from the iterative design process and provided in Table 8. 


\section{Summary of Approaches to Capstone Courses from Other Universities}

The 3D quadcopter project is one example that clearly illustrates the system engineering approach. Other students successfully demonstrated system-level thinking and submitted projects that include: (1) Auto-Fetch Dog System, (2) Remote Control Unmanned Vehicle (RCUV) Cellular Link, (3) Caber Adventure GoPro Gimbal Project, and (4) Bulk SMS Software for Kenyan Schools ${ }^{1}$.

After experiencing success with the system engineering approach with several projects using the Vee Model in the MSEE program, other engineering colleges were investigated on how they implemented the capstone courses. The investigation revealed elements of system engineering are included in the capstone. However, the research did not reveal a formal use of the Vee Model in a capstone course. Key findings of the investigation are given below.

To bolster competency of engineering professions, Wasson proposes a competency in system engineering to strengthen undergraduate and graduate engineering programs ${ }^{6}$. Wasson cites that engineering projects tend to be component-centric. Wasson ${ }^{6}$ and Erwin ${ }^{7}$ discusses projects in engineering schools that receive little or no guidance or direction concerning the design process. Samson and Lowery ${ }^{8}$ notes that engineering graduates are missing system engineering skills as well as communications and interpersonal skills. The study emphasizes that engineers with five years' experience "spend most of their working time in meetings, collaborating with colleagues, participating in system development activities and decisions, and continue to build on their discipline knowledge." ${ }^{8}$ Wasson also identified a need to integrate SE concepts, principles, and practices into engineering programs. This will significantly upgrade the knowledge and skills of new engineering graduates to meet demands of the public and private workforce ${ }^{6}$.

At the undergraduate level, the Western Kentucky University created a new Systems Engineering (SE) Minor to upper division civil, electrical, and mechanical engineering ${ }^{9}$. The intent is to prepare the student for their capstone design course. Their course consists of systems engineering process, requirements, design fundamentals, subsystem fundamentals, trade studies, integration, technical reviews, and case studies and ethics. The minor in SE offers students to expand their perspective on understanding of systems and how effective management can better prepare them to address many complex and engineering challenges. Their students expressed that this course is a valuable pre-requisite to their capstone design courses. ${ }^{9}$

San Diego State University integrated systems engineering into a senior design course ${ }^{10}$. The paper explains that system design in mechanical engineering courses are limited to graduate courses nationwide. This approach creates an educational gap in understanding system-level requirements. The paper describes a basic approach to integrate the fundamentals of Systems Engineering into the design process ${ }^{10}$. This activity was accomplished using a system-level diagram that was continuously updated. The system-level diagram played a key role during synthesis, tradeoff, analysis, fabrication, assembly and testing phases of the project.

Several surveys were conducted in capstone engineering courses to provide snapshots of practices $^{10-13}$. These studies found that the structure, logistics and implementation of capstone courses vary widely. The discussion below provides a glimpse into the capstone design practices 
and trends gathered from the surveys. Again, the surveys did not reveal the specific use of the Vee model as a tool to implement and document the system engineering process. However, some elements of the design process have concepts associated with System Engineering.

A 2010 survey by Howe ${ }^{10}$ summarized that $61 \%$ of the survey responses in 1994 study $^{11}$ identified oral communication as a topic in capstone courses. The same study summarized the 2005 survey $^{12}$ responses of 343 institutions and identified the following topics taught in capstone courses (number of respondents): written communication (87), oral communication (83), ethics (76), project planning and scheduling (72), decision making (68) plus many more but none of the topics revealed specific system engineering processes.

The 2010 study focused on five major categories but did not focus on details and deliverables of the design process:

- Respondents with half of capstone programs are less than ten years old in 2005

- Course/project logistics where external project sourcing, either through industry or design competitions as the most common approach

- Faculty involvement with either most or very few faculty in general with most receiving teaching credit

- Funding details with most project costs less than $\$ 1000$

- Industry Sponsors ranging in location from local to national but mostly from local or regional sponsors

The study notes that industry sponsors provide relevance to the project and student motivation to successfully complete the project. System engineering is especially important when it comes to the military and NASA. As a side note, the local area of the authors' campus has a heavy military presence with many programs being classified. The engineering student for the university project is a foreign national which makes it difficult to get access but is still a cumbersome process even if the student is a U.S. resident. Fortunately, the student was extremely motivated to complete his complex project.

Another 2015 survey $^{13}$ of capstone courses repeated questions from its 1994 and 2005 predecessors $^{11-12}$ but included additional questions. Most of the 522 respondents from 256 institutions came from the U.S. with a handful of programs from other countries. One of the focused areas of the study include qualitative responses on implementation practices. As mentioned in previous surveys, capstone courses across engineering programs are common in the U.S but they vary significantly in implementation. Of the 95 of 361 responded that a professional setting was a key teaching theme in the capstone course. In this survey, professional setting includes: simulate authentic practice, real-world projects, interim reports and meetings, and keeping up with new and emerging technologies. Eighty respondents replied to experience objectives. The experience objectives include the following topics: oral and written communication skills; hands-on learning; student professional development; opportunities for creativity and innovation; application of concepts learned in class; emphasis on justifying decisions; entrepreneurship; analysis and optimization; risk mitigation; open-endedness; sustainability; life-cycle costing; balancing challenge and fun; balancing and results. 
In the same 2015 study $^{11}$, one of the categories for typical deliverables require 'evidence of the design process'. Of the 328 respondents, only 79 (approximately 25\%) responded to this category. This category includes: design process documentation, design specifications, project notebook or logbook; design reviews; design history file or record.

Based on the surveys and investigation of other engineering capstone courses, the authors believe that the Vee Model provides a systematic structure that can be adapted to meet a wide range of capstone objectives. The model provides the students guidance to mirror a real-world experience and to provide documentation of their design process and system-level thinking. The Vee Model provides a systematic method for student deliverables showing evidence of the design process. This model provides a balance between system-level thinking and component-level design skills to produce a solution or product.

\section{Investigation of Other Similar 3D-Printed and Arduino Quadcopter Capstone Projects}

The 3D-printed quadcopter was a technically challenging and motivating project for the student. The project also provided real-world experience to show how system engineering and its documentation are used to provide a process and form a functional solution. Thus, other capstone projects were investigated that involve 3D-printed and Arduino quadcopters. However, the investigation revealed few of these quadcopter projects. Below is a summary and sample of the investigation.

Numerous web resources were found providing information that involves building 3D-printed and Arduino projects. One website, Instructables.com ${ }^{14}$, has one project to develop 3D-printed quadcopters based on the Arducopter ${ }^{15}$ kit. Several projects were found based on the Arducopter consisting of a metal-based frame and an Arduino microcontroller.

One recent project that had these elements was from Morocco at Akhawayn University ${ }^{16}$. The quadcopter intends to provide a stable platform for a micro-projector. However, the project did not reveal any formal system engineering process. Their approach involves several factors: Societal, Technical, Environmental, Ethical, Political and Legal, and Economic issues (or STEEPE) analysis. The report did not describe the micro-projector and its application. A system architecture was defined and project requirements were given. The attempt of the flight test failed.

There was one 3D-Printed Quadcopter involving a multidisciplinary team resulting Academic Training program ${ }^{17}$. The project objective is to design, build, test and fly a quadcopter within ten weeks' duration (30/40 hours per week). They used an off-the-shelf remote controller and flight controller. The students built the quadcopter frame with 3D-printed parts. Elements of the design process were included but the paper did not reveal a formal system engineering process.

In summary, the investigation revealed few capstone projects involving 3D-printed and Arduino projects. Below is a summary and sample of the investigation that attempts to find other quadcopter projects that includes the system engineering process.

On research team at the University of Pennsylvania called GRASP (General Robotics, Automation, Sensing \& Perception) Lab involves coordinating a swarm of quadcopters. One 
program investigated the possibility of single-motor operation for micro aerial vehicles (MAV) ${ }^{18}$. The proof-of-concept involves using wind pressure to perform passive stability. The initial proof-of-concept featured two micro-aerial vehicles (MAV): (1) based on a single actuator-a component of a machine that is responsible for moving or controlling a mechanism or system; and (2) established passive stability primarily through wind pressure. The investigation revealed elements of the design process but did not reveal a formal system engineering process.

Professor Santiago mentored a multi-disciplinary team on a drone project at the USAF Academy (USAFA) in 1984-1989 at the Department of Electrical Engineering (now Electrical and Computer Engineering). At that time, some elements of the design process involved system engineering such as a Preliminary Design Review and Critical Design Review. During that time, the USAFA program did not offer a system engineering degree like it does now.

USAFA cadets and their mentors developed an Unmanned Aerial Vehicle (UAV) Program with an emphasis on coordination among UAVs. The USAFA instructors published numerous articles on cadet UAV projects. One paper described how they implemented system engineering concepts using an approach called Just-In-Time teaching so that immediate lessons were taught on any engineering issues raised by the students ${ }^{19}$. This approach increased student motivation and retention as evidenced by their improved designs and system engineering products. The first semester is focus on Requirements and Definition, Test Plan while the second semester includes hardware and software development and documentation. The documentation includes a: Final Test Plan, Preliminary Design Review, Critical Design Review final report and a final presentation to include system verification. The same paper identified that adding students with System Engineering or System Management majors to the multi-disciplinary team, resulted in better control and documentation of the requirements. The program had an extensive mentoring system with two mentors and several subject matter experts not normally found in other universities. The investigation did find any capstone projects from the USAF Academy dealing with 3D-printed and Arduino quadcopters.

There are numerous examples of capstone of quadcopter projects ${ }^{20-23}$ but the investigation did not reveal 3D-printed quadcopters, Arduino, and a structured system engineering process. However, elements of the design process have been found in some of the research.

\section{Comparison of Popular Commercial Drones}

During the 11-week project, the student was not task to compare the cost of his prototype with other commercial drones. However, the authors attempted to compare the cost as depicted in Table 9. The table attempts to provide of comparison of some popular drones with the student's prototype $^{24-25}$.

\begin{tabular}{|l|l|l|}
\hline Drone & Price & Key Specifications/Comments \\
\hline Student Drone Prototype & $\$ 1,200$ without camera & $\begin{array}{l}\text { Altitude up to 100 meter, } \\
\text { Controllable up to 800 meters, 900- } \\
\text { gram payload, 3.2 kg weight } \\
\text { without payload, 15-minute flight } \\
\text { time with loaded payload, 30- }\end{array}$ \\
\hline
\end{tabular}




\begin{tabular}{|l|l|l|}
\hline & & $\begin{array}{l}\text { minute hover time with no payload } \\
\text { using } 8000 \text { mAh, capable of stable } \\
\text { alignment of any direction (e.g. } \\
\text { north pole), user-input tilt } \\
\text { orientation recharged in less than } \\
\text { two hours }\end{array}$ \\
\hline DJI Phantom 4 Pro & $\$ 1,500$ & $\begin{array}{l}\text { Aerial videography, 3-axis gimbal } \\
\text { mount, 4k camera, failsafe } \\
\text { protection for battery running low } \\
\text { or lose control range, 25-28 } \\
\text { minutes' flight time and flight } \\
\text { distance of 1.2 miles, obstacle } \\
\text { avoidance, 1.39 kg weight }\end{array}$ \\
\hline DJI Inspire s1000 & $\$ 4,550$ & $\begin{array}{l}\text { For professional aerographer and } \\
\text { cinematographer, 3-axis gimbal, } \\
\text { Flight Time - 15 minutes, Total } \\
\text { Weight - 4.2 kg, Takeoff Weight: } \\
\text { 6-11 kg, Octocopter, video digital } \\
\text { downlink, autopilot function, fold- } \\
\text { up arms, retractable landing gear, } \\
\text { additional IMU for increased } \\
\text { stability }\end{array}$ \\
\hline DJI Inspire 1 & $\$ 1,900$ & $\begin{array}{l}\text { Weight 3 kg, Flight time 15-18 } \\
\text { minutes with 4500 mAh, 20-22 } \\
\text { minutes with 5799 mAh }\end{array}$ \\
\hline
\end{tabular}

Table 9. Comparison of Popular Commercial Drone with Student Drone Prototype

The student prototype is comparable in terms of weight and flight time when compared to DJI Inspire 1. In terms of flight time with payload, the student compares well with DJI Inspire 1 where the student drone uses larger batteries. In terms of performance of stable video images, the student did not have time to test the video capability of the quadcopter and stability performance of video flyovers. The student also did not integrate a 3-axis gimbal for the camera on the quadcopter. In terms of range, the student prototype does not exceed the requirement of 1.2 miles of the DJI Phantom 4 Pro. Thus, the level of performance of the prototype drone is currently not on par with today's commercial drones such as the more capable and expensive DJI Inspire s1000. However, the authors observed that the student learned many topics and performed system engineering tradeoffs when putting the various components together. The tradeoffs were supported by detailed analysis in selecting the hardware components for the quadcopter to meet system requirements. In addition, the student applied key electrical and computer engineering principles to meet overall requirements of the system.

In terms of cost, the $\$ 1200$ drone prototype may be viable as a kit for those who just want to learn how to build a quadcopter. However, there are some capstone and student projects that use the Arducopter kit as a baseline to develop a drone prototype. The Arducopter can be purchased for less than $\$ 800$. For aerial photography and heavy lifting, DIY drone kits are available ranging from $\$ 1150$ to $\$ 1500$. As mentioned earlier, video stability of images has not been tested at 
various angle orientations with the student drone. For STEM teaching, there are currently less expensive toy versions of DIY Drone starter kits, ranging from $\$ 40$ to $\$ 60$.

\section{Conclusion}

The College of Engineering successfully incorporated systems engineering concepts into a graduate capstone course in electrical engineering. The approach expands the student experience by providing them with a more holistic view of engineering. This was accomplished by having the student think more at the system level and from a variety of perspectives. The student presented the solution communicating a message having an economic and societal value. The system-level thinking builds upon the specialized technical skills from other courses found in the University's graduate engineering programs. The student acquired new skills while making connections and leveraging the skills from the graduate program. The capstone course attempts to provide a right mix of technical merit, systems engineering thinking, and improved communication skills.

The 3D quadcopter project is one example that clearly illustrates the system engineering approach. Other students successfully demonstrated system-level thinking and submitted projects that include: (1) Auto-Fetch Dog System, (2) Remote Control Unmanned Vehicle (RCUV) Cellular Link, (3) Caber Adventure GoPro Gimbal Project, and (4) Bulk SMS Software for Kenyan Schools ${ }^{1}$.

\section{References}

1. Santiago, John and Jing Guo, "A System Engineering Approach for Implementing An Electrical or Computer Engineering Master's Capstone Course”, ASEE Rocky Mountain Section Conference, Cedar City, Utah, 2016 2. Blanchard, S. Benjamin, Wolter Frabrycky, "System engineering and Analysis" (Fifth Edition), Prentice Hall, New Jersey, 2011, pg. 37 (Vee-Model)

3. Buede, Dennis, "The Engineering Design of Systems - Models and Methods" (Second Edition), Wiley, 2009, pg. $10-12$

4. Sage, Andrew P. James E. Armstrong, Jr., "Introduction to System Engineering”, Wiley, 2009, pg. 78.

5. Information retrieved from student deliverables for EE 692, Electrical Engineering Capstone, March 2015.

6. Wasson, Charles S, System Engineering Competency: The Missing Course in Engineering Education, ASEE, 2012

7. Erwin, Ben. K-12 Education and Systems Engineering: A New Perspective, Proceedings of the American Society of Engineering Education (ASEE) National Conference, Session 1280,

Seattle, WA, July 1998, p. 6.

8. Samson, Charles H, and Lowery, Lee L., "The Need for Systems Engineering Education," Proceedings of the Third Annual International Symposium, National Council on Systems Engineering (NCOSE), Arlington, VA, July $26-28,1993$, p. 1 .

9. Choate, Robert and Stacy S. Wilson, "The Impact of a Systems Engineering Course on Capstone Project Performance, 2015 ASEE Southeast Section Conference.

10. Howe, Susan, Advances in Engineering Education, Where Are We Now? Statistics on Capstone Courses Nationwide, ASEE, 2010.

11. Todd, Robert, Spencer Magleby, Carl Sorenson, Bret Swan, and David Anthony. "A Survey of Capstone Engineering Courses in North America.” Journal of Engineering Education (April 1995): 165-174,

http://www.asee.org/publications/jee/PAPERS/display.cfm?pdf=29.pdf 
12. Howe, Susannah and Jessica Wilbarger. "2005 National Survey of Engineering Capstone Design Courses." Proceedings of the 2006 ASEE Annual Conference and Exposition (2006), http://soa.asee.org/paper/conference/paper-view.cfm?id=1983

13. Howe, Susannah, Sophia Poulos, Laura Rosenbauer, "2015 Capstone Design Survey: Observations from the Front Lines", ASEE 123 ${ }^{\text {rd }}$ Annual Conference and Exposition, New Orleans, LA, Jun 26-29, 2016.

14. http://www.instructables.com/id/3D-Printed-Quadcopter-with-Arduino/?ALLSTEPS

15. ArduCopter - more than your average quadcopter, Retrieved from http://www.arducopter.co.uk/

16. El Kihal, Mohammed, "Development of a Flying Projector: The Quadcopter Support" Capstone Report, Al Akhawayn, University, Morocco23 Nov 2016.

Retrieved from http://www.aui.ma/sse-capstonerepository/pdf/DevelopmentofaFlyingProjectorTheQuadcopterSupport.pdf.

17. Radharamanan, R., "Use of 3-D Printers to Design, Build, and Test a Quadcopter Drone", 123th ASEE Annual and Exposition, New Orleans, LA, June 26-29, 2016.

18. Piccoli, Matthew and Mark Yim, "Passive Stability of a Single Actuator Micro Aerial Vehicle," May 2014. Retrieved from http://www.modlabupenn.org/wp-content/uploads/Passive-Stability-of-a-Single-Actuator-MAV.pdf and https://3dprint.com/154646/3d-printed-self-flying-vehicle.

19. Wicker, James, et al, A Multi-Disciplinary Senior Design Project Using Cooperative Unmanned Aerial Vehicles, 2011 ASEE Annual Conference \& Exposition, Vancouver, BC

20. Cox, Jordan, "Lighter than Air UAV", ASEE 2014 Zone I Conference, April 3-5, 2014, University of Bridgeport, Bridgeport, CT, USA.

21. Dustin Jack Hallenbeck, MAKER: Stronger Frames by Mimicking Nature, $120^{\text {th }}$ ASEE Annual Conference and Exposition, New Orleans, LA, 2016.

22. Minaie, Afsaneh, et al, Capstone Projects in a Computer Engineering Program Using Arduino, $120^{\text {th }}$ ASEE Annual Conference and Exposition, Atlanta, GA, Jun 23-26

23. Maxwell, Shawn, Rajin Roophnath, "Miniature Wireless Quadcopter", ASEE 2014 Zone I Conference, April 35, 2014, University of Bridgeport, Bridgpeort, CT, USA.

24. Retrieved from https://buythebestdrone.com/best-commercial-drones/

25. Retrieved from http://www.droneguru.net/the-best-commercial-drones-for-sale-right-now/ 